\title{
A Study on Children's Preference for Tourist Destinations Based on Naive Theory
}

\author{
Liu Yan $^{1}$ \\ ${ }^{1}$ School of Tourism and Service Management, Chongqing University of Education,Chongqing, China
}

\begin{abstract}
At present, the lack of both supply and theory in children tourism is due to the long-term habit of placing children in the opposite or attached state of ethics of adults, and the "scenery" in the eyes of children haven't received due attention. Therefore, to link and verify children's naïve psychology and tourism behavior in many dimensions substantially, to study children's preference characteristics for types, landscape, recreation of tourism destinations and other self-constructed preference characteristics and causality with tourism behavior, can provide concrete and reliable empirical basis for children's tourism academic research, industry practice and policy design.
\end{abstract}

\section{INTRODUCTION}

With nearly 5 million children under the age of 14 in Chongqing, the number of children will peak in 2020 with the gradual release of the reproductive potential brought about by the overall "second child". Optimizing the environment for children's growth and actively carrying out various forms of popular science and social practice activities has become the main task of Planning for Children in Chongqing (2011-2020). Tourism as an important practical way to achieve the above tasks and goals, has been unanimously recognized and adopted by the government, families and even schools. However, although the tourism industry has launched a wide variety of tourism products for children, but the original tourism activities have not changed substantially, which has led to great disappointment for both children and parents; on the other hand, the research on children's tourism has just started. As of April 2020, the number of academic papers in Chinese databases such as "Children Tourism in Chongqing", "Family trip" and other keywords searched CNKI is hardly any, and only a few papers on "Field Trip, Educational Tourism, Study Tourism, Learning Travel in Chongqing" have been published. This shows that the research on children tourism in Chongqing still lacks the excellent guide which can benefit the practice of the industry. The reason for the double deficiency of supply and theory is that people have long used to put children in the opposite or attached state of ethics of adults, and the society and tourism industry have not really paid due attention to the "scenery" in the eyes of children.

Therefore, optimizing the research perspective of children tourism, from paying attention to what kind of tourism products can be provided to children to what kind of tourism preferences children have, from the orig- inal researcher's "subjective" to children's own "constructive " research paradigm, can better understand children's cognition of the tourism process, and help all parties to grasp children's tourism psychology and behavior characteristics; to supply tourism and leisure products suitable to the needs of children and to explore the formation of a system with continuous improvement of the quality of children tourism products.

\section{THEORY AND METHODOLOGY}

Naive theory is an important theory about the mechanism of children's autonomous cognition. since its emergence in the1970s, it has been an important subject in the study of children's developmental psychology. The theory holds that children themselves have accumulated a series of knowledge of the objective world and also a framework for causal interpretation of it before learning scientific theory, including naive physics (such as cognition of physical phenomena including natural scenery, seasonal changes, temperature differences, climate change, etc.), naive psychology (such as cognition of peer relationships, family roles, emotions, emotions, etc.) and naive biology (such as cognition of old age, illness and death). This theory should prove the objective existence of children's informal, non-scientific understanding and explanation of things and phenomena in daily life, overturn the traditional judgment that "young children know nothing about the world", and provide a theoretical basis for children to seek better expression of their demands. Therefore, from the perspective of this

aly818359@sina.com 


\section{SURVEY}

\subsection{Sample selection}

The Educational Science Institute Huayu Experimental School was selected as the research site, because it is the largest compulsory education school in Jiangbei District in Chongqing, which has a large sample size base, and on the other hand, it has a comprehensive sample type. After consultation with the school leaders and taking into account the differences in students' cognition and learning situation, the study finally selected the second, third and fifth grade students as the sample of research. (the reason is that the first grade are really too young to understand the subject painting ability is limited to participate in the survey, so the junior section of the survey was designated as the second grade. And the fourth grade had group activities during the research period, so the third grade become the sample of the middle section chose. In addition, the sixth grade are busy with the examination, and do not have the time conditions for research.

\subsection{Process implementation}

The study began in mid-December 2019 and lasted three weeks before the winter vacation in primary school on January 15,2020 . The theme of the study was "one of your favorite tourist activities". Before painting, the researchers explained the purpose of the study to the children involved in the study in an easy-to-understand form and let them paint according to their own perception and feelings. At the end of the day, the researchers, coordinated by the teacher in charge of the class, sampled their paintings at intervals of 10 and randomly to let the children give a description about their paintings, including the following questions: what had you painted? Why did you draw that scene? What was the impression of the tour? ...... and recorded. This stage was actually a process in which children and adults (researchers, professionals, etc.) constructed meaning around research problems. Children were extremely central to this stage, and researchers didn't interfere with or guide their explanatory notes, refining children's preferences for tourist destinations based solely on retained data and follow-up dialogues.

\subsection{Data collection}

The study collected 340 paintings, including 134 in the second grade ,156 in the third grade and 77 in the fifth grade. A total of 53 paintings (34 in the second grade ,16 in the third grade, and 3 in the fifth grade, see Figure1.) were removed and 314 valid samples were obtained, constituting a proportional Table1. It must be noted that the authors of the paintings are not indicated below, taking into account the children's privacy protection, but the pictures cited are derived from the real paintings of the subject and all the charts are based on the data obtained from the relevant research.

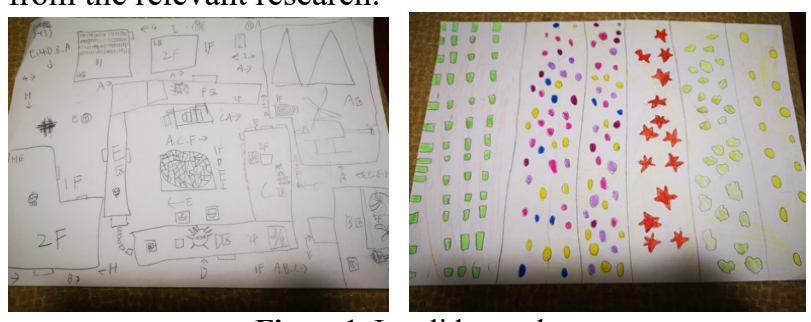

Figure1. Invalid sample

TABLE I. VALID SAMPLE

\begin{tabular}{|c|c|c|}
\hline Grade & $\begin{array}{c}\text { Number of sam- } \\
\text { ples }\end{array}$ & $\begin{array}{c}\text { Percentage of } \\
\text { valid samples }\end{array}$ \\
\hline The second & 100 & $32 \%$ \\
\hline The third & 140 & $44 \%$ \\
\hline The fifith & 74 & $24 \%$ \\
\hline Total & 314 & $100 \%$ \\
\hline
\end{tabular}

\section{ANALYSIS OF THE FINDINGS}

\subsection{Children's preference for types of tourist destinations}

Tourist destination is combination of tourism resources in a certain geographical space with tourism special facilities, tourism infrastructure and other related conditions, which is the center of tourist activities. Understanding children's tendentious cognition of types of tourist destinations can provide principles for strengthen tourist destination image orientation and function integration. According to the classification of tourist destination resources and the characteristics of survey objects, the tourist destination can be divided into five types: natural scenery, leisure and entertainment, modern metropolis, ancient city and religion, science technology and culture. Based on this classification, the findings of the children's preference for different types of tourist destinations is shown in Table.2, and some samples are shown in Fig .2- Fig .5.

\begin{tabular}{ccccccc} 
TABLE II. & STYLESSTATISTICS ON CHILERENIS PERFERENCE FOR TYPESE OF TOURIST DESTINATIONS \\
\hline Age & $\begin{array}{c}\text { Number } \\
\text { of samples }\end{array}$ & $\begin{array}{c}\text { Natural scen- } \\
\text { ery }\end{array}$ & $\begin{array}{c}\text { Leisure and en- } \\
\text { tertainment }\end{array}$ & $\begin{array}{c}\text { Modern me- } \\
\text { tropolis }\end{array}$ & $\begin{array}{c}\text { Ancient city } \\
\text { and religion }\end{array}$ & $\begin{array}{c}\text { Science tech- } \\
\text { nology and } \\
\text { culture }\end{array}$ \\
\hline $\begin{array}{c}\text { The sec- } \\
\text { ond } \\
\text { grade }\end{array}$ & 100 & $10(10 \%)$ & $36(36 \%)$ & $20(20 \%)$ & $21(21 \%)$ & $13(13 \%)$ \\
$\begin{array}{c}\text { The third } \\
\text { grade }\end{array}$ & 140 & $2(18.6 \%)$ & $81(57.9 \%)$ & $1(12.9 \%)$ & $7(5 \%)$ & $8(5.7 \%)$ \\
$\begin{array}{c}\text { The fifth } \\
\text { grade }\end{array}$ & 74 & $3(43.2 \%)$ & $22(29.7 \%)$ & $6(8.1 \%)$ & $6(8.1 \%)$ & $8(10.8 \%)$ \\
\hline
\end{tabular}




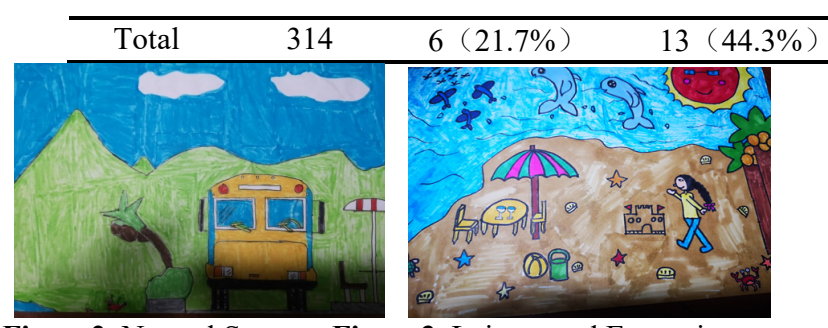

Figure2. Natural Scenery Figure3. Leisure and Entertainment

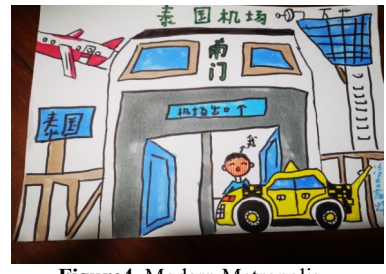

Figure4. Modern Metropolis

igures Ancient city and Religion

The study found that children's preference for leisure and entertainment tourist destinations accounted for an absolute proportion of the five destination types. Painting scenes such as "beach swimming, lake fishing, mountaineering, playground playing" appeared many times, in the visit to children such as "Happy Valley", "Jihua Garden" and other theme park words have also been mentioned many times. The results coincide with the statistics of China's online tourism development data index report 2018 on "The most popular leisure and entertainment scenic spots" in China today. It shows that with the coming of the leisure era and the increase of parents' paid time, the children's activity probability to the leisure and entertainment tourist destination is greatly increased, which strengthens the children's perception preference to this kind of tourist destination. In addition, this result is also related to the children's preference for play, and the fact that most of the respondents come from cities, and they prefer places with similar living environment, convenient regional transportation, and wellknown entertainment scenic spots. The research also found that children in the lower grades had preference for science and technology obviously. This reflects the children's strong desire to explore the unknown world, but also to a certain extent reflects the current integration of literature and tourism, smart tourism and other new forms of tourism development trends on children's invisible impact. In addition, the data show that with the increase of age, children's preference for natural scenery is on the rise, probably because the older children can use the knowledge they have learned to appreciate the fa-

$44(14 \%) \quad 3(10.8 \%) \quad 29(9.2 \%)$

mous and magnificent beauty of the motherland with the increase of experience. In addition to natural scenery and leisure and entertainment destinations, the fifth grade's perception of the other three types is near the average value, which also shows that the children's cognitive level is improved, and the demand for tourism is no longer limited to the shallow visual satisfaction brought by natural landscape sightseeing. They have started a deeper level of independent thinking and gradually explored multiple types of tourist destinations. Children in all grades of the study prefer modern metropolis, which to some extent reflects the charm of Chongqing as a popular tourist destination, and the internal influence of Chongqing's urban living environment on children's preference for tourist destinations.

\subsection{Children's preference for landscape of tourist destinations}

Tourism landscape refers to the collection of visual scenes that attract tourists in a certain area. With the development of all-for-one tourism, the tourist destination should exist all landscape attractions. The aesthetic experience of tourists, including children tourists, may happen at any time. Therefore, the investigation of children's visual preference for landscape can provide an important basis for tourist destination to accurately strengthen its resource characteristics and optimize landscape design. Statistics show that the landscape in tourist destination described in this sample can be roughly divided into seven types: peers, mountains and rivers, plants, animals, architecture, food and facilities. The data show (see Table 3 ) that children have the highest awareness of play facilities, and that children's love of play is fully justified in the findings for play facilities in the tourist destination. On the one hand, Chongqing food has been integrated into daily life, thus deducting children's enthusiasm for other food destinations. In addition, most of the children have drawn and mentioned the presences of peers in the travel process, especially the lower grade children. This shows that the travel mode of younger children is usually based on the arrangement of family, or the school collective, and the children's own travel preferences will usually be obscured by family decisions or school planning behavior.

TABLE III. STASTISTICS ON CHILDREN'S PREFERENCE FOR LANDSCAPE OF TOURIST DESTIONATIONS

\begin{tabular}{ccccccccc}
\hline Age & $\begin{array}{c}\text { Number } \\
\text { of sam- } \\
\text { ples }\end{array}$ & Peers & $\begin{array}{c}\text { Mountains } \\
\text { and rivers }\end{array}$ & Plants & Animals & Architecture & Food & Facilities \\
\hline $\begin{array}{c}\text { The } \\
\text { second } \\
\text { grade }\end{array}$ & 100 & 82 & 10 & 26 & 11 & 32 & 10 & 58 \\
$\begin{array}{c}\text { The } \\
\text { third } \\
\text { grade }\end{array}$ & 140 & 112 & 26 & 32 & 8 & 32 & 8 & 81 \\
$\begin{array}{c}\text { The } \\
\text { fifth } \\
\text { grade }\end{array}$ & 74 & 32 & 32 & 8 & 5 & 18 & 4 & 22 \\
Total & 314 & 126 & 68 & 66 & 24 & 82 & 22 & 161 \\
\hline
\end{tabular}




\subsection{Children's preference for recreational activities of tourist destinations}

Recreational activities are the sum of the processes of a series of actions aimed at leisure. Children's most primitive nature is to play, so whether the tourist destination can provide them with a fully released nature of recreational activities design directly affects children's preference perception. In the research, children's painting works and narration showed their preferences for a wide variety of recreational activities, such as swimming, boating, fishing, skiing, playing games, amusement parks playing, picking fruit, even walking dogs, drinking covered bowls of tea, riding hot air balloons, and so on (see Fig .6- Fig .10). According to statistics: their favorite recreational activities mainly focus on swimming, amusement park playing and playing games (see Table 4), especially amusement park playing. And the younger children obviously prefer to play such naive recreational activities. With the gradual increase of age, the change of cognitive level and mode of thinking, the cultural activities based on children's own cognition and rational thinking are gradually becoming more attractive to children, and the older children gradually turn to participate in colorful cultural and leisure activities, including appreciating architecture and antiques, experiencing traditional culture etiquettes, experiencing high technology and so on. In a word, with the increase of grade and knowledge, children's preference is also changed from pure sightseeing to aesthetic appreciation of nature and recognition of the world.

TABLE IV. STASTISTICS ON CHILDREN'S PREFERENCE FOR RECREATIONAL ACTIVITIES OF TOURIST DESTINATIONS

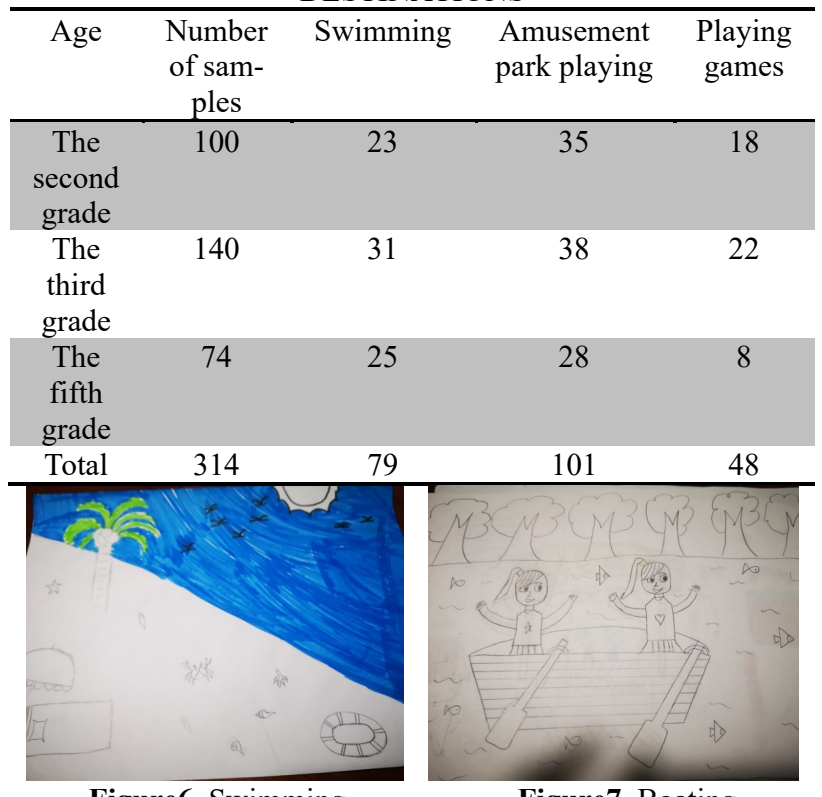

Figure6. Swimming

Figure7. Boating
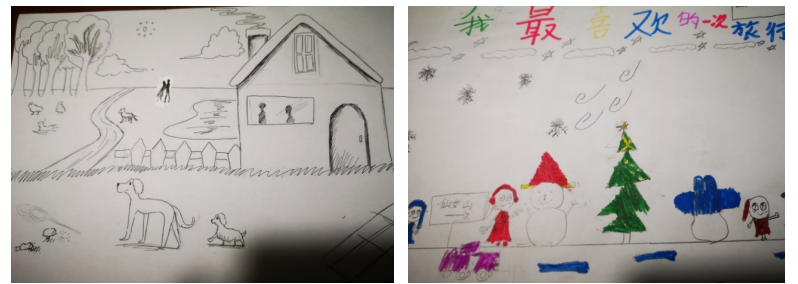

Figure8. Walking dogs

Figure9. skiing

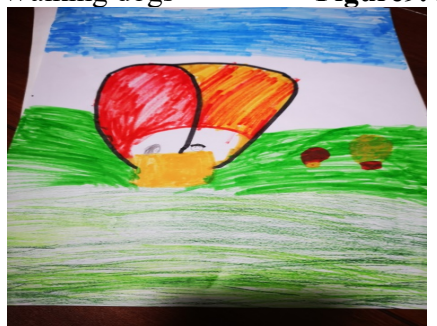

Figure10. Hot air balloon riding

\section{CONLUSION}

According to the naive theory of children's intuitive psychology, through the Mosaic method, the study obtained the typical data of children's intuitive preferences for tourist destinations. According to the above research results, tourist destinations should be further optimized in terms of market segmentation, product design, information transmission to provide more suitable and excellent tourism products for children's needs. At the same time, tourism academic research can further explore children's cognition of physical phenomena, peer relation, emotional changes and other deeper research topics according to the naïve theory.

\subsection{Market segmentation}

Children with different personal characteristics clearly have different preferences for tourist destinations. As a result, Tourist destinations should further segment the children's market group according to the age, sex, family structure, residence and other subdivision variables, select the target market suitable for exerting their own strength and advantages, and design more children tourism products with prominent themes according to the demand of the target children market accordingly.

\subsection{Product design}

According to children's particular preference for recreational activities and recreational facilities, tourist destinations should develop diversified thematic recreational activities such as fantastic and confusing hot air balloon trips, lively and interesting rural picking trips, colorful study tours, etc. Or combined with the current children's favorite film and television works or book games and other designed activities, meanwhile combining tourism school-based curriculum to teach children tourism knowledge and skills, cultivate civilized tourism habits. Besides, tourist destination should set up more entertainment facilities such as floating bridge, slide, climbing equipment, carousel, etc. according to different theme functions. 


\subsection{Information transmission}

The study found that children's perceived impressions of the destination are constructed in a diverse way, definitely tourist destinations should use a variety of new-media marketing promotion strategies that children like to see for advertising, communicating and interacting effectively, so that tourism marketing close to children's tourism needs, strengthen children's tourism perception. For example, tourist propaganda films, tourist advertisements or tourist websites can use children's preferred fashion cartoon image to reinforce the impression of a tourist destination's landmark logo or core attraction in the mind of children. Or they can use the time when children participate in parent-child travel to pay attention to the form of WeChat official account for tourism destination marketing, and also can use tourism virtual technology to let children directly carry out the first experience of tourism destination and so on.

\section{AUTHOR}

Liu Yan (1981-). Associate professor, The research direction: Regional tourism development.

\section{SUPPORTING PROJECTS}

1.Project Supported by Scientific and Technological Research Program of Chongqing Municipal Education Commission (KJQN201901602);
2.Project Supported by Humanities and Social Sciences Research Program of Chongqing Municipal Education Commission (18SKGH156);

3.Collaborative Centre for Research and Application in Child Research Travel (2017XJPT02);

4.Children's Etiquette Teaching Studio of Chongqing Urban-Rural Teacher Education Research Center (JDGZS201605)

\section{REFERENCES}

1. Fu Taisheng. A Naive Biology Theory for Preschool Children: Concept, Connotation and Enlightenment[J].Journal of Inner Mongolia Normal University(Educational Science Edition)2019(10):45 51

2. Wang Fang, Wu Bihu, Luo Ruixue. Study on ParentChild Tourism Experience and its Promotion Countermeasures -Based on the Perspective of Children's Painting Projection [J]. Chinese University Journal (Philosophy and Social Sciences Edition),2017(5):35 50

3. Feng Xiaohong, Li Mimi. A Review of Child Tourism [J].] Tourism Journal ,2016(9):61 71

4. Huang Xiaoting, Liu Chun: The Influence of Travel Peer Role on Tourist Behavior —— Taking Hong Kong Ocean Park as an Example [J].] Human Geography ,2016(2)2:128 135

5. Xu Yanping. A Research Report on Children's "Naive Theory" [J].] Early education. 2014(3): 1 7 